\title{
Breast cancer survival by molecular subtype: a population- based analysis of cancer registry data
}

\author{
Saber Fallahpour PhD, Tanya Navaneelan MSc, Prithwish De PhD, Alessia Borgo MPH
}

\section{Abstract}

Background: The relation between breast cancer molecular subtype and survival has been studied in several jurisdictions, but limited information is available for Ontario. The aim of this study was to determine breast cancer survival by molecular subtype and to assess the effect on survival of selected demographic and tumour-based characteristics.

Methods: We extracted 29833 breast cancer cases (in 26538 girls and women aged $\geq 15$ yr) diagnosed between 2010 and 2012 from the Ontario Cancer Registry. Cancers were categorized into 4 molecular subtypes: 1) luminal A (estrogen-receptor-positive and/or progesterone-receptor-positive [ER+ and/or $\mathrm{PR}+]$ and negative for human epidermal growth factor receptor 2 [HER2-]), 2) luminal $B(E R+$ and/or PR+/HER2+), 3) HER2-enriched (ER- and PR-/HER2+) and 4) triple-negative (ER- and PR-/HER2-). We estimated associations with predictor variables (age, stage at diagnosis, histologic type, comorbidity and place of residence [urban or rural]) using a multivariate Cox proportional hazards model. Likelihood ratio testing was used to evaluate differences in risk of death.

Results: Luminal A was the most commonly diagnosed subtype (59.0\%) and had the greatest survival, whereas triple-negative had the poorest survival. For all subtypes, a dose-response effect was observed between the hazard of death and age and stage at diagnosis, with the greatest effect found for the HER2-enriched subtype (age: hazard ratio [HR] 7.87 [95\% confidence interval (Cl) 3.6811.81]; stage at diagnosis: HR 37.71 [95\% Cl 34.64-41.27]). Moderate comorbidity (Charlson Comorbidity Index score 1 or 2 ) was associated with increased risk of death for triple-negative cancers (HR 2.42 [95\% Cl 1.36-4.31]), and severe comorbidity (Charlson Comorbidity Index score $\geq 3$ ) increased the risk for all molecular subtypes.

Interpretation: The results indicate the importance of including molecular subtype, along with age, stage at diagnosis and comorbidity, in assessing breast cancer survival. They highlight the need to address outcomes related to hormone-receptor-negative cancers, for which survival lags behind that for hormone-receptor-positive cancers.

$\mathrm{B}$ reast cancer is the most commonly diagnosed cancer and the second most common cause of cancer-related death among women in Ontario. ${ }^{1}$ More than 10000 cases are diagnosed each year in the province. ${ }^{1}$ Several molecular subtypes of breast cancer have been identified based on hormone receptor and human epidermal growth factor receptor 2 (HER2) status. ${ }^{2}$ These molecular subtypes have been shown to affect survival: patients with hormone-receptor-negative tumours tend have greater mortality and lower survival than those with hormone-receptor-positive tumours. ${ }^{3-5}$

Although the relation between breast cancer molecular subtype and survival has been studied in other jurisdictions, including British Columbia, ${ }^{6,7}$ limited information is available for Ontario. The goal of this study was to determine how breast cancer molecular subtype affects survival among Ontario women and how survival for each subtype varies by selected demographic and tumour-based characteristics.

\section{Methods}

\section{Setting and study population}

The study population included all cases of malignant breast cancer diagnosed in girls and women aged 15 years or more in Ontario between Jan. 1, 2010, and Dec. 31, 2012. We chose this period because data on molecular subtype were unavailable for cases diagnosed before 2010, and mortality data were unavailable for cases diagnosed after 2012.

Competing interests: None declared.

This article has been peer reviewed.

Correspondence to: Saber Fallahpour, saber.fallahpour@ cancercare.on.ca CMAJ Open 2017. DOI:10.9778/cmajo.20170030 


\section{Data sources and definitions}

The data for this study were extracted from the July 2016 version of the Ontario Cancer Registry, a population-based database of new cancer cases. The registry covers the entire population of Ontario and includes information about all cases of invasive neoplasia diagnosed in the province since 1964 except for basal cell and squamous cell skin cancers. Quality measures for the 2012 diagnosis year with the data-quality standard of the North American Association of Central Cancer Registries were as follows: completeness of case ascertainment (94.8\%), missing age and missing sex $(0 \%)$, cases with death certificate only $(1.8 \%)$ and passing North American Association of Central Cancer Registries edit checks (100\%). ${ }^{8}$ Breast cancer incident cases and deaths were classified as C50 according to the International Classification of Diseases for Oncology, 3rd edition $^{9}$ and the International Statistical Classification of Diseases and Related Health Problems, 10th revision. ${ }^{10}$

Predictor variables of interest were age, histologic type, stage at diagnosis, comorbidity and residence at diagnosis. Histologic type was defined as ductal (histology codes 8201, 8230, 8401, 8500-8504, 8507, 8508, 8523, 8541, 8543), lobular (histology codes 8520-8522, 8524) or other. We classified stage at diagnosis using the Collaborative Staging method, which incorporates information on tumour size, lymph node involvement and metastases. ${ }^{11}$ Information on molecular subtype was collected from coded synoptic pathology reports, which are submitted electronically to the Ontario Cancer Registry by public and private laboratories. We extracted data on comorbidities from the Canadian Institute for Health Information's Discharge Abstract Database and linked them using health card number. Comorbidities were organized according to the Charlson Comorbidity Index. ${ }^{12}$ Comorbidity categories are weighted from 1 to 6 , with a score of 0 indicating no comorbid conditions. We determined residence (rural or urban) at the time of diagnosis using the Postal Code Conversion File Plus package. ${ }^{13}$

\section{Molecular subtypes}

We categorized breast cancer cases into 4 molecular subtypes based on hormone receptor and HER2 status. Hormonereceptive-positive tumours can be sensitive to exposure to either estrogen (estrogen-receptor-positive [ER+]) or progesterone (progesterone-receptor-positive $[\mathrm{PR}+]$ ) or not sensitive to either hormone (hormone-receptor-negative [ER- or PR-]). Tumours that are HER2-positive (HER2+) overproduce the HER2 protein that stimulates uncontrolled breast cell proliferation. This results in 4 molecular subtypes: luminal A (ER+ and/or PR+/HER2-), luminal B (ER+ and/or $\mathrm{PR}+/ \mathrm{HER} 2+$ ), HER2-enriched (ER- and PR-/HER2 + ) and triple-negative (ER- and PR-/HER2-).

\section{Statistical analysis}

We calculated survival as the time (in days) between the patient's date of diagnosis and 1 of the following, whichever occurred first: 1) date of death, 2) date last known to be alive or 3 ) the most recent follow-up cut-off date (Dec. 31, 2012). The outcome of interest was death due to breast cancer; deaths from other causes were censored at the date of death.
We used SAS statistical software (version 9.4) (SAS Institute) to perform the analysis. A univariate model was performed to compare survival among the molecular subtypes. We estimated associations between molecular subtype and the predictor variables using the Cox proportional hazards model. Four separate multivariate Cox models were fitted for each molecular subtype, and the association with predictors was investigated within each model. No interactions between variables were found in any model. We investigated the proportionality assumption for each variable through the log-log survival function as well as the computed $p$ value of a Kolmogorov-type supremum test based on a sample of 1000 simulated residual patterns. With the exception of stage at diagnosis, none of the variables in the models violated the proportionality assumption. To make stage at diagnosis satisfy the proportionality assumption, we regrouped the variable (stage I and II v. stage III v. stage IV). We used likelihood ratio testing to evaluate whether the variations in risk of death by variable were statistically significant.

\section{Ethics approval}

Because this was secondary analysis of data, no ethics approval was sought.

\section{Results}

\section{Incidence counts and rates}

A total of 29833 cases of breast cancer (in 26538 individual girls and women) were included in the incidence analysis. Table 1 presents the incidence counts and rates for each molecular subtype by age group. The luminal A subtype was the subtype most commonly diagnosed, accounting for $59.0 \%$ of all cases, with a rate of 103.3 per 100000 , followed by triple-negative (15.1 per 100000$)$, luminal B (13.5 per $100000)$ and HER2-enriched (7.0 per 100000$)$.

The incidence rate of the luminal A subtype peaked among patients aged 70-79 years (262.1 per 100 000). The incidence of luminal B cancers was much more evenly distributed, with similar rates among patients aged 50-59, 60-69 and 70-79. The rate of HER2-enriched cancers peaked among those aged 50-59 (12.9 per 100000$)$, and the distribution was most skewed toward the younger age groups. For triple-negative cancers, the distribution was skewed more toward the oldest age groups, with the highest rates found among those aged 60 or more.

\section{Survival}

Of the 26538 patients, 4000 were excluded from the survival analysis: 3777 had multiple primary cancers or were missing health card number, stage or receptor status, and 223 had an autopsy or death certificate only. This resulted in a final sample of 22538 patients in whom breast cancer was diagnosed for the first time between 2010 and 2012.

Table 2 presents the number of patients and observed breast cancer deaths for each molecular subtype by the variables used in the Cox regression analysis. Regardless of molecular subtype, mortality was higher among patients with more advanced age, severe comorbidity (Charlson Comorbidity 
Index score $\geq 3$ ), advanced stage at diagnosis (stage III or IV), lobular carcinoma and urban residence.

Univariate analysis showed significant differences in survival between the molecular subtypes $(p<0.001)$ (Figure 1). Pairwise comparisons using log-rank tests also showed that survival differed significantly between each molecular subtype, with patients with the luminal A subtype experiencing the longest survival, followed by those with the luminal B and HER2-enriched subtypes. The poorest survival was observed among patients with the triple-negative subtype.

Cox regression analysis showed that, for all molecular subtypes, age at diagnosis, histologic type (except for HER2enriched), stage at diagnosis and comorbidity were the significant contributors to the hazard of death (Table 3).

\section{Age at diagnosis}

Age at diagnosis was significantly associated with death for all molecular subtypes. For all subtypes, there was a dose-response relation with age, with the hazard of death increasing with increasing age, although which age groups had significantly higher hazard of death differed by subtype. Among patients with luminal A cancer, increasing age was associated with increased risk of death for women aged 60 or more. Among those with luminal B or HER2-enriched cancers, however, increased risk over the reference level was found only for those aged 80 or more. Age had the greatest effect on the hazard of death for HER2-enriched cancers, with patients aged 80 or more having almost 8 times the risk of those aged 15-49. For triple-negative cancers, the hazard of death was increased for women aged 70 or more. Age at diagnosis had the smallest effect on triple-negative cancers, with patients aged 80 or more having only a twofold increase in the risk of death compared to those aged 15-49.

\section{Histologic type}

Histologic type was a significant predictor of survival for all molecular subtypes except HER2-enriched. There was no sig- nificant difference in risk of death between ductal and lobular carcinoma regardless of molecular subtype. However, for the luminal A, luminal B and triple-negative subtypes, patients with cancers classified as "other" had increased survival compared to those with ductal carcinomas. The greatest increase in survival in the "other" group was seen for patients with luminal A cancer, who had less than a quarter the risk of death of those with ductal cancers.

\section{Stage at diagnosis}

For all molecular subtypes, stage at diagnosis was the strongest predictor of survival. Across all subtypes, patients with stage III or IV cancer had a significantly increased hazard of death compared to those with stage I or II disease. For all subtypes, there was a dose response-relation with stage at diagnosis, with the hazard of death increasing with increasing stage. The greatest increase in the hazard of death was observed for HER2-enriched cancers: patients with stage III cancer had almost 8 times the risk of death of those with stage I or II cancer, while women with stage IV disease had almost 38 times the risk.

\section{Comorbidity}

For the luminal A, luminal B and HER2-enriched molecular subtypes, patients with moderate comorbidity (Charlson Comorbidity Index score 1 or 2) had no increase in risk of death compared to those with no comorbid conditions. For the triple-negative subtype, a dose-response relation with level of comorbidity was observed: patients with moderate comorbidity had 2.2 times the risk of death of those with no comorbid conditions, and patients with severe comorbidity (Charlson Comorbidity Index score $\geq 3$ ) had 3.4 times the risk. Severe comorbidity increased the risk of death for all molecular subtypes, with the greatest effect found for luminal $\mathrm{B}$ cancers, for which the risk was 6 times higher (twice the effect seen for the other 3 subtypes).

Table 1: Breast cancer cases and age-specific incidence rates (per 100 000) by molecular subtype, Ontario, 2010-2012

\begin{tabular}{|c|c|c|c|c|c|c|c|c|c|c|c|c|}
\hline \multirow[b]{3}{*}{$\begin{array}{l}\text { Molecular } \\
\text { subtype }\end{array}$} & \multicolumn{12}{|c|}{ Age group, yr } \\
\hline & \multicolumn{2}{|c|}{ All ages } & \multicolumn{2}{|c|}{$15-49$} & \multicolumn{2}{|c|}{$50-59$} & \multicolumn{2}{|c|}{$60-69$} & \multicolumn{2}{|c|}{$70-79$} & \multicolumn{2}{|c|}{$\geq 80$} \\
\hline & $\begin{array}{c}\text { Count } \\
(\%)\end{array}$ & $\begin{array}{c}\text { Incidence } \\
\text { rate per } \\
100000\end{array}$ & $\begin{array}{c}\text { Count } \\
(\%)\end{array}$ & $\begin{array}{l}\text { Incidence } \\
\text { rate per } \\
100000\end{array}$ & $\begin{array}{c}\text { Count } \\
(\%)\end{array}$ & $\begin{array}{l}\text { Incidence } \\
\text { rate per } \\
100000\end{array}$ & $\begin{array}{c}\text { Count } \\
(\%)\end{array}$ & $\begin{array}{c}\text { Incidence } \\
\text { rate per } \\
100000\end{array}$ & $\begin{array}{c}\text { Count } \\
(\%)\end{array}$ & $\begin{array}{l}\text { Incidence } \\
\text { rate per } \\
100000\end{array}$ & $\begin{array}{c}\text { Count } \\
(\%)\end{array}$ & $\begin{array}{c}\text { Incidence } \\
\text { rate per } \\
100000\end{array}$ \\
\hline Luminal A & $\begin{array}{c}17598 \\
(59.0)\end{array}$ & 103.3 & $\begin{array}{l}3238 \\
(54.5)\end{array}$ & 33.1 & $\begin{array}{c}4085 \\
(58.1)\end{array}$ & 141.3 & $\begin{array}{c}4789 \\
(62.4)\end{array}$ & 230.4 & $\begin{array}{l}3403 \\
(62.4)\end{array}$ & 262.1 & $\begin{array}{l}2083 \\
(55.8)\end{array}$ & 213.5 \\
\hline Luminal B & $\begin{array}{c}2308 \\
(7.7)\end{array}$ & 13.5 & $\begin{array}{c}704 \\
(11.8)\end{array}$ & 7.2 & $\begin{array}{c}660 \\
(9.4)\end{array}$ & 22.8 & $\begin{array}{c}494 \\
(6.4)\end{array}$ & 23.8 & $\begin{array}{l}287 \\
(5.3)\end{array}$ & 22.1 & $\begin{array}{c}163 \\
(4.4)\end{array}$ & 16.7 \\
\hline $\begin{array}{l}\text { HER2- } \\
\text { enriched }\end{array}$ & $\begin{array}{l}1193 \\
(4.0)\end{array}$ & 7.0 & $\begin{array}{c}337 \\
(5.7)\end{array}$ & 3.4 & $\begin{array}{c}372 \\
(5.3)\end{array}$ & 12.9 & $\begin{array}{l}261 \\
(3.4)\end{array}$ & 12.6 & $\begin{array}{c}137 \\
(2.5)\end{array}$ & 10.6 & $\begin{array}{c}86 \\
(2.3)\end{array}$ & 8.8 \\
\hline $\begin{array}{l}\text { Triple- } \\
\text { negative }\end{array}$ & $\begin{array}{l}2574 \\
(8.6)\end{array}$ & 15.1 & $\begin{array}{c}669 \\
(11.3)\end{array}$ & 6.8 & $\begin{array}{c}638 \\
(9.1)\end{array}$ & 22.1 & $\begin{array}{l}606 \\
(7.9)\end{array}$ & 29.2 & $\begin{array}{l}386 \\
(7.1)\end{array}$ & 29.7 & $\begin{array}{l}275 \\
(7.4)\end{array}$ & 28.2 \\
\hline Unknown & $\begin{array}{c}6160 \\
(20.6)\end{array}$ & 36.2 & $\begin{array}{c}991 \\
(16.7)\end{array}$ & 10.1 & $\begin{array}{c}1278 \\
(18.2)\end{array}$ & 44.2 & $\begin{array}{c}1525 \\
(19.9)\end{array}$ & 73.4 & $\begin{array}{c}1239 \\
(22.7)\end{array}$ & 95.4 & $\begin{array}{c}1127 \\
(30.2)\end{array}$ & 115.5 \\
\hline Total & 29833 & 175.1 & 5939 & 60.7 & 7033 & 243.3 & 7675 & 369.2 & 5452 & 420 & 3734 & 382.7 \\
\hline
\end{tabular}




\begin{tabular}{|c|c|c|c|c|c|c|c|c|}
\hline \multirow[b]{3}{*}{ Variable } & \multicolumn{8}{|c|}{ Molecular subtype } \\
\hline & \multicolumn{2}{|c|}{ Luminal A } & \multicolumn{2}{|c|}{ Luminal B } & \multicolumn{2}{|c|}{ HER2-enriched } & \multicolumn{2}{|c|}{ Triple-negative } \\
\hline & $\begin{array}{l}\text { No. of deaths/ } \\
\text { no. of patients }\end{array}$ & $\begin{array}{c}\text { Cancer } \\
\text { deaths, } \\
\%\end{array}$ & $\begin{array}{l}\text { No. of deaths/ } \\
\text { no. of patients }\end{array}$ & $\begin{array}{c}\text { Cancer } \\
\text { deaths, } \\
\%\end{array}$ & $\begin{array}{l}\text { No. of deaths/ } \\
\text { no. of patients }\end{array}$ & $\begin{array}{c}\text { Cancer } \\
\text { deaths, } \\
\%\end{array}$ & $\begin{array}{l}\text { No. of deaths/ } \\
\text { no. of patients }\end{array}$ & $\begin{array}{c}\text { Cancer } \\
\text { deaths, } \\
\%\end{array}$ \\
\hline \multicolumn{9}{|l|}{ Age, yr } \\
\hline $15-49$ & $36 / 3157$ & 1.1 & $12 / 681$ & 1.8 & $12 / 333$ & 3.6 & $50 / 648$ & 7.7 \\
\hline $50-59$ & $55 / 3943$ & 1.4 & $14 / 640$ & 2.2 & $15 / 361$ & 4.2 & $35 / 599$ & 5.8 \\
\hline $60-69$ & $78 / 4559$ & 1.7 & $18 / 470$ & 3.8 & $15 / 253$ & 5.9 & $35 / 560$ & 6.2 \\
\hline $70-79$ & $83 / 3187$ & 2.6 & $7 / 262$ & 2.7 & $8 / 127$ & 6.3 & $47 / 368$ & 12.8 \\
\hline$\geq 80$ & $109 / 1915$ & 5.7 & $23 / 147$ & 15.6 & $18 / 80$ & 22.5 & $41 / 248$ & 16.5 \\
\hline \multicolumn{9}{|c|}{$\begin{array}{l}\text { Residence at } \\
\text { diagnosis }\end{array}$} \\
\hline Urban & $325 / 14795$ & 2.2 & $68 / 1961$ & 3.5 & $61 / 1008$ & 6.0 & $185 / 2131$ & 8.7 \\
\hline Rural & $36 / 1966$ & 1.8 & $6 / 239$ & 2.5 & $7 / 146$ & 4.8 & 23/292 & 7.9 \\
\hline \multicolumn{9}{|c|}{ Histologic type } \\
\hline Ductal & 268/10 663 & 2.5 & $58 / 1468$ & 4.0 & $55 / 859$ & 6.4 & $161 / 1744$ & 9.2 \\
\hline Lobular & $64 / 2105$ & 3.0 & $7 / 165$ & 4.2 & $3 / 35$ & 8.6 & $9 / 42$ & 21.4 \\
\hline Other & 29/3993 & 0.7 & $9 / 567$ & 1.6 & $10 / 260$ & 3.8 & $38 / 637$ & 6.0 \\
\hline \multicolumn{9}{|c|}{ Stage at diagnosis } \\
\hline I-II & $100 / 14046$ & 0.7 & $16 / 1579$ & 1.0 & $7 / 745$ & 0.9 & $66 / 1866$ & 3.5 \\
\hline III & $93 / 2080$ & 4.5 & $12 / 480$ & 2.5 & $23 / 304$ & 7.6 & $81 / 440$ & 18.4 \\
\hline IV & $168 / 635$ & 26.4 & $46 / 141$ & 32.6 & $38 / 105$ & 36.2 & $61 / 117$ & 52.1 \\
\hline \multicolumn{9}{|c|}{$\begin{array}{l}\text { Charlson Comorbidity } \\
\text { Index score }\end{array}$} \\
\hline 0 & $243 / 15493$ & 1.6 & $39 / 2021$ & 1.9 & $43 / 1028$ & 4.2 & $163 / 2238$ & 7.3 \\
\hline $1-2$ & $20 / 550$ & 3.6 & $5 / 46$ & 10.9 & $4 / 34$ & 11.8 & $14 / 76$ & 18.4 \\
\hline$\geq 3$ & $98 / 718$ & 13.6 & $30 / 133$ & 22.6 & $21 / 92$ & 22.8 & $31 / 109$ & 28.4 \\
\hline Total & $361 / 16761$ & 2.2 & $74 / 2200$ & 3.4 & $68 / 1154$ & 5.9 & $208 / 2423$ & 8.6 \\
\hline
\end{tabular}

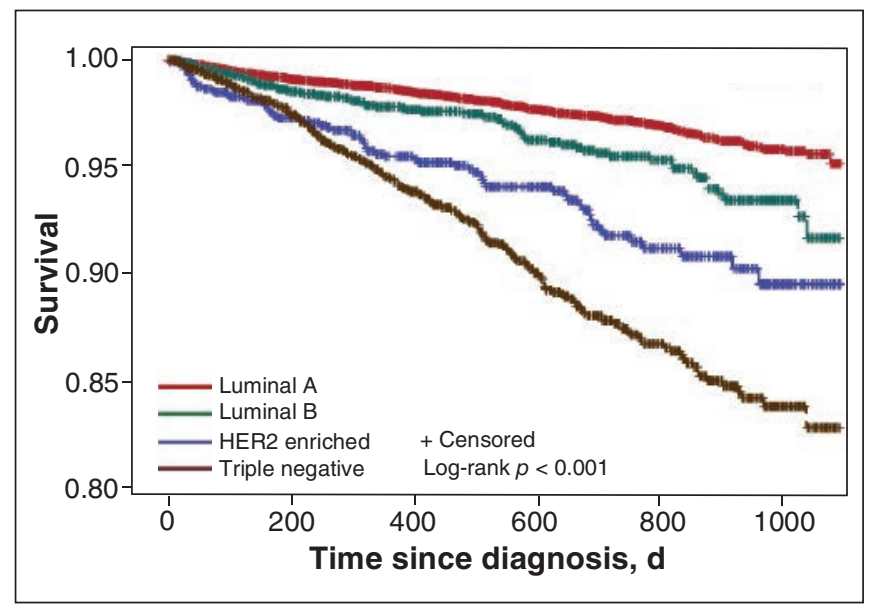

Figure 1: Kaplan-Meier plot of overall breast cancer survival by molecular subtype, Ontario, 2010-2012. Note: HER2 = human epidermal growth factor receptor 2 .

\section{Interpretation}

This analysis illustrates the heterogeneous nature of female breast cancer with regard to molecular subtype in Ontario. Most female breast cancers diagnosed between 2010 and 2012 were luminal A cancers, the subtype with the greatest survival. However, the second most common type was triple-negative, the subtype with the poorest survival. Age, histologic type, stage at diagnosis and comorbidity were all found to affect survival. Stage at diagnosis was the strongest predictor of survival, with patients with stage IV disease having a $27-$ to 38 -fold increase in risk of death, depending on the molecular subtype, compared to those with stage I-II disease.

In this analysis, luminal A cancers accounted for $59.0 \%$ of all breast cancers. This is higher than the proportion found in other Canadian studies, $41 \%-44 \%{ }^{6,7}$ Previous analyses have shown that the incidence of hormone-receptor-negative cancers tends to peak before menopause, whereas hormone-receptor-positive cancers are more common after menopause. ${ }^{1-16}$ The incidence 


\section{OPEN}

Research

of triple-negative cancers in our study did not conform to these findings, peaking in postmenopausal women (aged $\geq 60$ ).

We found that survival was highest for patients with luminal A cancers, followed by those with luminal B cancers. This confirms the better outcomes in hormone-receptor-positive cancers reported in other jurisdictions. ${ }^{6,7,17-19} \mathrm{We}$ found no difference in survival between lobular and ductal histologic types among any of the molecular subtypes, despite the fact that lobular cancers tend to be associated with better prognosis. ${ }^{20-22} \mathrm{We}$ also found no difference in survival between urban and rural residents, regardless of molecular subtype, even though rural Canadians often lag behind urban Canadians in many health indicators, such as life expectancy. ${ }^{23}$ This result is similar to that in a previous study of breast cancer outcomes in BC, which showed no difference between rural and urban women in either breast cancer or overall survival. ${ }^{24}$ However, as postulated in the BC study, the length of follow-up in the current analysis may not have been sufficient to detect significant differences. Nevertheless, the absence of a difference in survival between rural and urban residents is a positive sign of equity in breast cancer outcomes in Ontario.

\section{Limitations}

There are several possible confounders that we were unable to include in this analysis because data were not available. These include race, which has been shown to affect the risk of hormone-receptor-negative cancers ${ }^{25,26}$ and survival within subtypes; $;^{27-29}$ tobacco use, which has been associated with increased risk of hormone-receptor-negative cancers in postmenopausal women; ${ }^{30}$ obesity, which has been linked with an increased risk of hormone-receptor-positive cancers ${ }^{31-33}$ and, for premenopausal women, triple-negative cancers; ${ }^{34,35}$ and reproductive factors such as age at menarche, parity, oral contraceptive use and breastfeeding history, which have also been shown to affect the risk of hormone-receptor-positive cancers. ${ }^{30,31}$ Including these variables in our analysis may have adjusted the hazard ratios. In addition, data on treatment were not included in the analysis, as concerns about the quality of the treatment data currently available in Ontario meant that the possible informative value of the data did not outweigh the possible bias they may have introduced. Other investigators used additional molecular subtypes; ${ }^{6}$ however, identification of these additional subtypes was not possible in the current analysis, as

Table 3: Breast cancer survival hazard ratios, multivariate model, by molecular subtype and patient characteristics

\begin{tabular}{|c|c|c|c|c|}
\hline \multirow[b]{2}{*}{ Variable } & \multicolumn{4}{|c|}{ Molecular subtype; HR (95\% Cl) } \\
\hline & Luminal A & Luminal B & HER2-enriched & Triple-negative \\
\hline \multicolumn{5}{|l|}{ Age, yr } \\
\hline $15-49$ & Reference & Reference & Reference & Reference \\
\hline $50-59$ & $1.33(0.87-2.03)$ & $1.24(0.56-2.73)$ & $1.54(0.72-3.33)$ & $0.77(0.50-1.20)$ \\
\hline $60-69$ & $1.81(1.21-2.68)$ & $1.91(0.89-3.27)$ & $1.82(0.844-3.93)$ & $0.73(0.46-1.13)$ \\
\hline $70-79$ & $2.29(1.54-3.41)$ & $1.05(0.402-2.73)$ & $2.04(0.77-4.41)$ & $1.73(1.11-2.70)$ \\
\hline$\geq 80$ & $4.13(2.81-6.07)$ & $6.34(2.88-11.06)$ & $7.87(3.68-11.81)$ & $1.77(1.18-2.65)$ \\
\hline \multicolumn{5}{|c|}{ Residence at diagnosis } \\
\hline Urban & Reference & Reference & Reference & Reference \\
\hline Rural & $0.85(0.60-1.21)$ & $1.34(0.57-3.14)$ & $0.91(0.40-1.64)$ & $0.97(0.63-1.51)$ \\
\hline \multicolumn{5}{|c|}{ Histologic type } \\
\hline Ductal & Reference & Reference & Reference & Reference \\
\hline Lobular & $0.83(0.63-1.09)$ & $0.46(0.19-1.09)$ & $1.27(0.34-3.21)$ & $1.84(0.92-2.67)$ \\
\hline Other & $0.22(0.15-0.33)$ & $0.42(0.21-0.87)$ & $0.61(0.29-1.24)$ & $0.68(0.47-0.97)$ \\
\hline \multicolumn{5}{|c|}{ Stage at diagnosis } \\
\hline I-II & Reference & Reference & Reference & Reference \\
\hline III & $6.52(4.89-8.69)$ & $2.14(1.02-4.58)$ & $7.86(4.33-11.52)$ & $5.49(3.93-7.66)$ \\
\hline IV & $27.05(24.41-31.29)$ & $34.32(30.48-39.73)$ & $37.71(34.64-41.27)$ & $27.02(24.76-28.82)$ \\
\hline \multicolumn{5}{|c|}{$\begin{array}{l}\text { Charlson Comorbidity } \\
\text { Index score }\end{array}$} \\
\hline 0 & Reference & Reference & Reference & Reference \\
\hline $1-2$ & 1.59 (0.98-2.54) & $1.37(0.49-3.17)$ & $1.84(0.62-3.51)$ & $2.42(1.36-4.31)$ \\
\hline$\geq 3$ & 2.54 (1.98-3.27) & $5.94(3.48-8.13)$ & $2.54(1.47-4.44)$ & $3.41(2.61-4.62)$ \\
\hline
\end{tabular}


the data did not allow for the inclusion of Ki-67, epidermal growth factor receptor or cytokeratin $5 / 6$ status. We had to use a broad age range for the younger patients (15-49 yr), as the case counts were too low to allow for smaller groups. Finally, the length of follow-up ( $3 \mathrm{yr}$ ) may be considered short. However, as the goal was to present current survival, not to predict future survival, we believe the follow-up period was adequate.

\section{Conclusion}

Survival among girls and women with breast cancer in Ontario was found to vary considerably by molecular subtype. The results indicate a need to address outcomes related to the treatment and/or detection of hormone-receptor-negative cancers, for which survival lags behind that for hormone-receptorpositive cancers. The prognosis and treatment of patients with breast cancer may be improved by also taking into account age, stage at diagnosis and comorbidity in relation to their tumour hormone status. Once more data are available, further analysis on this topic, including trends over time, will be possible. This could be a fruitful area of investigation, as other jurisdictions have found that survival has improved more for estrogen-positive tumours than for other subtypes. ${ }^{36-40}$

\section{References}

1. Ontario cancer statistics 2016. Toronto: Cancer Care Ontario; 2016.

2. Goldhirsch A, Wood WC, Coates AS, et al.; Panel members. Strategies for subtypes - dealing with the diversity of breast cancer: highlights of the St. Gallen International Expert Consensus on the Primary Therapy of Early Breast Cancer 2011. Ann Oncol 2011;22:1736-47.

3. Grann VR, Troxel AB, Zojwalla NJ, et al. Hormone receptor status and survival in a population-based cohort of patients with breast carcinoma. Cancer 2005;103:2241-51

4. Ravdin PM, Green S, Dorr TM, et al. Prognostic significance of progesterone receptor levels in estrogen receptor-positive patients with metastatic breast cancer treated with tamoxifen: results of a prospective Southwest Oncology Group study. 7 Clin Oncol 1992;10:1284-91.

5. Shek LL, Godolphin W, Spinelli JJ. Oestrogen receptors, nodes and stage as predictors of post-recurrence survival in 457 breast cancer patients. Br 7 Cancer 1987;56:825-9

6. Voduc KD, Cheang MC, Tyldesley S, et al. Breast cancer subtypes and the risk of local and regional relapse. F Clin Oncol 2010;28:1684-91.

7. Kennecke H, Yerushalmi R, Woods R, et al. Metastatic behavior of breast cancer subtypes. 7 Clin Oncol 2010;28:3271-7.

8. Prodhan S, King MJ, De P, et al. Health services data: the Ontario Cancer Registry (a unique, linked, and automated population-based registry). In: Sobolev B, Levy A, Goring S, editors. Data and measures in bealth services research. New York: Springer US; 2016.

9. Fritz A, Percy C, Jack A, et al., editors. International classification of diseases for oncology (ICD-O). 3rd ed., 1st rev. Geneva: World Health Organization; 2000.

10. International statistical classification of diseases and related bealth problems (ICD-10). 2nd ed., 10th rev. Geneva: World Health Organization; 2004.

11. Edge S, Byrd DR, Compton CC, editors. A7CC cancer staging handbook: from the cancer staging manual. New York: Springer-Verlag; 2010.

12. Charlson ME, Pompei P, Ales KL, et al. A new method of classifying prognostic comorbidity in longitudinal studies: development and validation. $\mathcal{F}$ Chronic Dis 1987;40:373-83.

13. Postal Code ${ }^{O M}$ Conversion File Plus (PCCF+) (82F0086X). Version 6A. Ottawa: Statistics Canada; 2015

14. Anderson WF, Chu KC, Chatterjee N, et al. Tumor variants by hormone receptor expression in white patients with node-negative breast cancer from the surveillance, epidemiology, and end results database. 7 Clin Oncol 2001;19: 18-27.

15. Yasui Y, Potter JD. The shape of age-incidence curves of female breast cancer by hormone-receptor status. Cancer Causes Control 1999;10:431-7.

16. Cadoo KA, Fornier MN, Morris PG. Biological subtypes of breast cancer: current concepts and implications for recurrence patterns. Q7 Nucl Med Mol Imaging 2013;57:312-21.

17. Bauer KR, Brown M, Cress RD, et al. Descriptive analysis of estrogen receptor (ER)-negative, progesterone receptor (PR)-negative, and HER2-negative invasive breast cancer, the so-called triple-negative phenotype: a population-based study from the California Cancer Registry. Cancer 2007;109:1721-8.
18. Carey LA, Perou CM, Livasy CA, et al. Race, breast cancer subtypes, and survival in the Carolina Breast Cancer Study. 7AMA 2006;295:2492-502.

19. Yang XR, Sherman ME, Rimm DL, et al. Differences in risk factors for breast cancer molecular subtypes in a population-based study. Cancer Epidemiol Biomarkers Prev 2007;16:439-43.

20. Wasif N, Maggard MA, Ko CY, et al. Invasive lobular vs. ductal breast cancer: a stage-matched comparison of outcomes. Ann Surg Oncol 2010;17:1862-9.

21. Toikkanen S, Pylkkanen L, Joensuu H. Invasive lobular carcinoma of the breast has better short- and long-term survival than invasive ductal carcinoma. $\mathrm{Br} F$ Cancer 1997;76:1234-40.

22. Dian D, Herold H, Mylonas I, et al. Survival analysis between patients with invasive ductal and invasive lobular breast cancer. Arch Gynecol Obstet 2009;279:23-8.

23. Kondro W. Health of rural Canadians lags behind urban counterparts. CMAf 2006;175:1195.

24. Olson RA, Nichol A, Caron NR, et al. Effect of community population size on breast cancer screening, stage distribution, treatment use and outcomes. Can $\mathcal{F}$ Public Health 2012;103:46-52.

25. Li CI, Malone KE, Daling JR. Differences in breast cancer hormone receptor status and histology by race and ethnicity among women 50 years of age and older. Cancer Epidemiol Biomarkers Prev 2002;11:601-7.

26. Chlebowski RT, Chen Z, Anderson GL, et al. Ethnicity and breast cancer: factor influencing differences in incidence and outcome. 7 Natl Cancer Inst 2005;97:439-48.

27. Sparano JA, Wang M, Zhao F, et al. Race and hormone receptor-positive breast cancer outcomes in a randomized chemotherapy trial. 7 Natl Cancer Inst 2012;104:406-14.

28. Tao L, Gomez SL, Keegan TH, et al. Breast cancer mortality in African-American and non-Hispanic white women by molecular subtype and stage at diagnosis: a population-based study. Cancer Epidemiol Biomarkers Prev 2015;24:1039-45.

29. Sullivan HC, Oprea-Ilies G, Adams AL, et al. Triple-negative breast carcinoma in African American and Caucasian women: clinicopathology, immunomarkers, and outcome. Appl Immunobistochem Mol Morphol 2014;22:17-23.

30. Cotterchio M, Kreiger N, Theis B, et al. Hormonal factors and the risk of breast cancer according to estrogen- and progesterone-receptor subgroup. Cancer Epidemiol Biomarkers Prev 2003;12:1053-60.

31. Althuis MD, Fergenbaum JH, Garcia-Closas M, et al. Etiology of hormone receptor-defined breast cancer: a systematic review of the literature. Cancer Epidemiol Biomarkers Prev 2004;13:1558-68.

32. Dolle JM, Daling JR, White E, et al. Risk factors for triple-negative breast cancer in women under the age of 45 years. Cancer Epidemiol Biomarkers Prev 2009; 18:1157-66.

33. Huang WY, Newman B, Millikan RC, et al. Hormone-related factors and risk of breast cancer in relation to estrogen receptor and progesterone receptor status. Am 7 Epidemiol 2000;151:703-14.

34. Yang XR, Chang-Claude J, Goode EL, et al. Associations of breast cancer risk factors with tumor subtypes: a pooled analysis from the Breast Cancer Association Consortium studies. 7 Natl Cancer Inst 2011;103:250-63.

35. Pierobon M, Frankenfeld CL. Obesity as a risk factor for triple-negative breast cancers: a systematic review and meta-analysis. Breast Cancer Res Treat 2013;137:307-14

36. Giordano SH, Buzdar AU, Smith TL, et al. Is breast cancer survival improving? Cancer 2004;100:44-52.

37. Holleczek B, Brenner H. Trends of population-based breast cancer survival in Germany and the US: decreasing discrepancies, but persistent survival gap of elderly patients in Germany. BMC Cancer 2012;12:317.

38. Jatoi I, Chen BE, Anderson WF, et al. Breast cancer mortality trends in the United States according to estrogen receptor status and age at diagnosis. 7 Clin Oncol 2007;25:1683-90.

39. Dunnwald LK, Rossing MA, Li CI. Hormone receptor status, tumor characteristics, and prognosis: a prospective cohort of breast cancer patients. Breast Cancer Res 2007;9:R6.

40. Ademuyiwa FO, Groman A, Hong CC, et al. Time-trends in survival in young women with breast cancer in a SEER population-based study. Breast Cancer Res Treat 2013;138:241-8

Affiliations: Surveillance and Cancer Registry (Fallahpour, Navaneelan, De) and ColonCancerCheck and Gastrointestinal Endoscopy (Borgo), Cancer Care Ontario, Toronto, Ont.

Contributors: Saber Fallahpour, Tanya Navaneelan and Prithwish De contributed to the study conception and revised the manuscript. Saber Fallahpour acquired the data and performed the data analysis, and Tanya Navaneelan interpreted the data. Saber Fallahpour and Tanya Navaneelan drafted the manuscript. All of the authors contributed to the study design, gave final approval of the version to be published and agreed to be accountable for all aspects of the work.

Acknowledgment: The authors acknowledge Cancer Care Ontario for assistance with funding for the publication fees for this paper.

Supplemental information: For reviewer comments and the original submission of this manuscript, please see www.cmajopen.ca/content $/ 5 / 3$ / E734/suppl/DC1. 